\title{
A psicanálise como ferramenta no complexo cenário do atendimento médico frente à criança portadora de paralisia cerebral
}

\author{
The psychoanalysis as a tool in the complex scenery of medical care \\ front of the child with cerebral palsy
}

\author{
${ }^{1}$ Walkiria Silva Soares Marins \\ ${ }^{2}$ Lilian Faro
}

\footnotetext{
1 Discente do Curso de Medicina do Centro Universitário de Volta Redonda - UniFOA. Enfermeira e Psicóloga pela UFF, Especialista em Saúde Pública pela FIOCRUZ / walkiriamarins@hotmail.com

2 Docente do curso de Medicina do Centro Universitário de Volta Redonda - UniFOA.
}

\section{RESUMO}

Este artigo se propõe a discutir a utilização de conceitos da psicanálise como ferramenta no complexo cenário do atendimento médico frente à criança portadora de paralisia cerebral (PC). Constituise de uma revisão de literatura que busca tratar da tríade pais-paciente-médico e das emoções e papéis que atravessam essas relações. A teoria e a prática se aglutinam como instrumento potencializador da intervenção clínica e preventiva do cuidado com essas crianças. A discussão do diagnóstico com a família, o questionamento aos estigmas sociais, a necessidade de se trabalhar sentimentos ocultos, auxiliando no processo de aceitação e ultrapassando a etapa da negação, são momentos em que a intervenção do médico pode simbolizar uma melhor adesão ao tratamento e melhor qualidade de vida para essa criança. A transferência e a contratransferência ganham um papel estruturante nessa relação que se constrói na tríade, promovendo comportamentos facilitadores ou prejudiciais ao tratamento.

\section{PALAVRAS-CHAVE}

Paralisia cerebral; relação; transferência; contratransferência.

\section{ABSTRACT}

This article aims to discuss the use of concepts of psychoanalysis as a tool in the complex scenery of medical care front of the child with cerebral palsy (CP). This is a revision literature that seeks to talk about the triad parent patient-doctor and the emotions and roles that croin this relationship. The theory and practice coalesce as a potentiator tool for clinical and preventive care intervention for these children. Discussion of diagnosis with family, questioning the social stigmas, hidden feelings work and, assist in the acceptance process bypassing the stage of denial, are moments where medical intervention can represent a better treatment adherence and improved quality of life for this child. The transference and countertransference earn a pivotal role in this relationship that is built on the triad, promoting facilitators or detrimental behaviors to treatment.

\section{KEYWORDS}

Cerebral paralysis; relationship; transference; countertransference.

\section{Como você deve citar?}

MARINS, W. S. S.; FARO, L. A psicanálise como ferramenta no complexo cenário do atendimento médico frente à criança portadora de paralisia cerebral. Cadernos UniFOA, Volta Redonda, ${ }^{\circ}$ 25, quadrimestral, p. 79-87, ago. 2014. 


\section{INTRODUÇÃO}

A relação médico-paciente, desde os primórdios da medicina, passara por diferentes momentos e atravessamentos teóricos. 0 advento da psicanálise trouxe consigo uma bagagem conceitual que veio a ampliar as discussões sobre as implicações nessa esfera da clínica.

0 atendimento à criança portadora de paralisia cerebral excede ao conhecimento técnico da medicina, já que a tríade pais-paciente-médico está imersa num cenário complexo de emoções, papéis, protótipos, ansiedade, frustrações, que exigem do profissional médico ferramentas psicológicas para penetrar nessa trama. A psicanálise vem ao encontro das lacunas e interrogações no atendimento médico, favorecendo a relação médico-paciente-pais como intervenção clínica e preventiva.

Este trabalho se propõe a fazer uma revisão de literatura que busque contribuir com reflexões que tangem ao campo da teoria e da práxis nesse amplo cenário alicerçado na transferência e contratransferência, onde todos os atores envolvidos estão implicados. Tem como objetivo destacar a importância da psicanálise como ferramenta para o médico no manejo das relações inseridas no atendimento às crianças portadoras de paralisia cerebral. Trata-se de um estudo de revisão de literatura de natureza qualitativa e de caráter exploratório. Foram utilizados como material: livros, artigos científicos e dissertações. Para seleção dos materiais escolhemos como critério livros de autores clássicos da psicanálise e da medicina como Freud, Lacan, Laplanche, Porto e Zimerman; artigos científicos e dissertações de 2007 a 2014 de pesquisados nas bases de dados da Bireme, Google Acadêmico e Scielo.

\section{O QUE VEM A SER PARALISIA CEREBRAL? MEU FILHO TEM ISSO?}

Receber um diagnóstico que trará implicações no desenvolvimento do filho para o resto de sua vida, não é algo tão simples, ainda mais quando não se sabe ao certo o significado real dele.

De acordo com CHAGAS (2008, p. 410) o termo paralisia cerebral designa "uma sequela de caráter não progressivo que acomete o sistema nervoso central imaturo e em desenvolvimento, ocasionando déficits posturais, tônicos e na execução de movimentos". "As desordens do desenvolvimento motor, advindas da lesão cerebral primária, são de caráter permanente e mutáveis, ocasionando alterações músculo-esqueléticas secundárias e limitações nas atividades" (ROSENBAUM, 2007).

Para REBEL (2010, p. 344), "a persistência dos reflexos primitivos e o atraso ou falha em adquirir reações posturais são indicadores precoces da disfunção do SNC. Os reflexos primitivos são mediados no tronco cerebral".

Segundo Ribeiro (2014, p. 441), "os pacientes podem apresentar déficit sensorial, intelectual e de comunicação".

Receber o diagnóstico de paralisia cerebral traz consigo uma série de estigmas sociais que geram nos pais da criança portadora um certo receio em relação a como tratar essa criança. Sabemos que, quando nos tornamos pais, não recebemos nenhum manual de orientação de como cuidar dos nossos filhos e, em geral, podemos nos sentir inseguros ao incorporamos esse papel que nos é atribuído pela sociedade. Como cuidar desse pequeno ser? Se já é difícil sermos pais, como será para aqueles que sabem que seus filhos necessitarão de cuidados especiais?

Em uma pesquisa realizada, em agosto de 2010, pela Associação de Pais e Amigos dos Excepcionais em Campina Grande (PB), SILVA (2010) nos mostra que a negação costuma ser a primeira reação dos 
pais ao saber que o filho tem um grave problema de saúde. Essa reação será tão mais intensa quanto maior for a possibilidade de a criança ter sequelas ou de correr risco de morte. Para as mães, a definição do diagnóstico foi motivo de surpresa, desespero, rejeição da criança, preocupação e insegurança.

De acordo com Dantas (2010, p. 236):

ao receber um diagnóstico desta natureza, vários processos são desencadeados, perpassando pelas fases de luto, choque, negação, aceitação e adaptação. Neste processo, as mudanças podem desencadear estresse, despertar sentimentos oscilantes, como amor e medo, que irão influenciar no modo como a família cuida do filho.

A descoberta de que seu filho será portador de uma deficiência gera, inicialmente, nos pais, um período de choque, depois de tristeza ou ansiedade, para em seguida e, gradualmente, ocorrer a aceitação da criança (MILBRATH, 2009, p. 438).

O começo da trajetória é caracterizado por desconhecimentos, dúvidas e sofrimento. No início, pode ser difícil perceber algo diferente na criança... Famílias que já tiveram outras crianças fazem comparações menos tardias, outras percebem a partir do momento que um profissional de saúde dá indícios de que a criança apresenta algo diferente. (ANDRADE, 2011, p. 95).

Para Bernardino (2007, p. 57):

no caso do anúncio de uma deficiência, o problema da criança é vivido como um defeito da mãe. É seu narcisismo que fica abalado e as reações inconscientes ao filho vão passar por extremos como negação, rejeição ou transformação no contrário ( a superproteção que mascara o desejo de morte)... Por outro lado, a entrada que a mãe normalmente daria ao pai, dirigindo seu desejo para ele e inscrevendo-o como terceiro na sua relação com o filho, vê-se obstruída por esta situação especial: de um filho deficiente é a mãe quem cuida...

\section{ASPECTOS EMOCIONAIS ENVOLVIDOS NO PROCESSO DE CONSTRUÇÃO INTERNA DO DIAGNÓSTICO}

Sabemos que, durante o processo de construção e compreensão do diagnóstico com a família, vários sentimentos são expostos, os protótipos são reorganizados na psique dos pais ou cuidadores e o emocional da criança em questão não pode ser esquecido.

A incompreensão, ou, até mesmo, em alguns casos, a negação das necessidades especiais decorrentes da paralisia
cerebral, por parte da família, pode levar a uma postergação do início do tratamento e, ao aumento das dificuldades

Sabemos, também, que o relacionamento que se estabelece na tríade país-filho-médico envolve um senso de responsabilidades com implicações diretas no futuro da criança com PC. "A PC acarreta mudanças, no que diz respeito às prioridades, vida social e expectativas da família. Para isso, a família cria estratégias de enfrentamento, embasadas no amor e na dedicação pela criança". (ANDRADE, 2011, p. 95).

Para Polita (2014, p. 80 e 81),

modelos de cuidado centrado na família são ideais para promoverem suporte, pois consideram o impacto da paralisia cerebral na família e respeitam a individualidade da criança e familiares. Também incluem a família no planejamento do cuidado, auxiliando no provimento de recursos físicos, espirituais, financeiros, sociais e biológicos, necessários para o enfrentamento da doença. 
Tendo em vista que a família atua no planejamento do cuidado e enfrentamento da doença, funcionando como suporte para a criança, percebemos que

o cuidar da criança, também, é cuidar de sua família. 0 apoio a mãe, ao pai ou outro integrante, permite que a família consiga aperfeiçoar suas habilidades, reduzir os seus medos, clarear suas fantasias, auxiliando-os a perceber a criança como um ser real, diminuindo o estereótipo de uma figura frágil... A ação de cuidar da família desencadeia nela a sensação de segurança ao não se perceber sozinha frente à responsabilidade de cuidar da criança. (MILBRATH, 2012, p. 924).

Acreditamos que as emoções estão implicadas intrinsecamente na construção interna do diagnóstico, principalmente entre os cuidadores. Para Marx et al (2011, p. 483): "a depressão e a ansiedade são doenças psiquiátricas comuns na população geral, mas parecem ser mais prevalentes entre os cuidadores de pessoas com doenças crônicas".

Em um estudo com 82 cuidadores de crianças com PC, realizado pela Associação de Pais e Amigos dos excepcionais (APAE) e pela Associação dos Deficientes Físicos de Alagoas (Adelaf), em Maceió Alagoas, observou-se alto índice de ansiedade (49\%) e de depressão ( $31 \%$ nos pais, percebendo-se que

entre os fatores que contribuem para o estabelecimento da ansiedade e depressão entre os cuidadores, deve se salientar a rotina estressante que têm a respeito da doença de suas crianças e do tratamento que elas requerem. (ZANON, 2012, p. 394).

\section{A TRANSFERÊNCIA E A CONTRATRANSFERÊNCIA NA TRÍADE PAIS-PACIENTE E MÉDICO}

O cenário está preparado, o diagnóstico passa a ser o enredo de nossa história, embalada ao som das emoções e conflitos que se instalam. Como a transferência e a contratransferência se delimitam nesse palco?

Podemos conceituar a transferência nas palavras de Porto (2014, p. 24):

\footnotetext{
O mecanismo de transferência diz respeito: aos fenômenos afetivos que o paciente passa (transfere) para a relação que estabelece com o médico. São sentimentos inconscientes vividos no âmbito de seus relacionamentos primários com os pais, irmãos e outros membros da família. Ao entrar em contato com o médico, o paciente revive nas profundezas de seu mundo emocional, em nível inconsciente, sentimentos nascidos e vivenciados nas relações primárias como se fossem situações novas.
}

Figueiredo (apud PALHARES, 2008, p. 102) nos mostra que:

a transferência ocorre espontaneamente em todas as relações humanas, já que é incessante este movimento de dentro para fora, de fora para dentro. Logo, a transferência emerge da vida, porque ela vai apontar para um infindável vir- a- ser, nesse sentido ela é estruturante.

Portanto, faz parte das relações humanas, inclusive na relação médico-paciente, como enfatiza Porto (2004): "Fala-se de transferência positiva quando o paciente vivencia o relacionamento de maneira agradável, confirmando a expectativa que tinha de encontrar no médico uma pessoa disponível, atenciosa e com capacidade para ajuda-lo".

Assim, temos de distinguir uma transferência positiva de uma negativa, a transferência de sentimentos afetuosos da dos hostis e tratar separadamente os dois tipos de transferência. 
Laplanche (2004, p. 518) afırma que "a transferência tanto na sua forma positiva como negativa, entra a serviço da resistência, mas nas mãos do médico, tornando-se o mais poderoso dos instrumentos terapêuticos".

Porto (2005, p. 1229) nos aponta sobre os sentimentos no enredo transferencial, registrando que

estes sentimentos, às vezes totalmente irracionais, que o paciente experimenta, derivam da identificação inconsciente que faz do médico com algum personagem significativo de sua infância (pais, irmãos, tios, babás). Sem se dar conta, o paciente atua em relação ao médico da mesma forma como aquele(s) personagem (ns) de sua infância: transfere para a relação médico- paciente a dinâmica psicológica de seus primeiros conflitos afetivos infantis, que marcaram de maneira permanente seu modo de reação inconsciente...A esse fenômeno de transferir cargas afetivas denomina-se transferência.

Freud, em suas obras completas (1996, p. 112), relata que

é inteligível que a catexia libidinal de alguém que se acha parcialmente insatisfeito, uma catexia que se acha pronta por antecipação, dirija-se também para a figura do médico. Decorre de nossas hipóteses primitivas que esta catexia recorrerá a protótipos, ligar-se-á a um dos clichês estereotípicos que se acham presentes no indivíduo,... a catexia incluíra o médico numa das séries psíquicas que o paciente já formou.

Para Laplanche (apud MENCARELLI, 2010, p. 31) a ideia de transferência se refere à repetição de protótipos infantis vividos com a sensação de atualidade acentuada que seria transferida para outro objeto. Lacan (apud SINGULANI, 2005, p. 90) afirma que

em sua emergência nos textos e nos ensinamentos de Freud, um deslizamento nos espreita, que não poderíamos imputar é de não ver no conceito de transferência senão o conceito mesmo de repetição. Não esqueçamos que quando Freud o representa para nós, ele nos diz- 0 que não pode ser rememorado se repete na conduta.

O conceito de contratransferência sofreu considerável evolução desde sua formulação inicial (ZIMERMAN, 2004). Quando Freud (1969) falava sobre suas inovações técnicas, na conferência de 1910, afirmava que as outras inovações na técnica relacionam-se com próprio médico. Dessa forma, torna-nos cientes da contratransferência, que nele (médico) surge como resultado da influência do paciente sobre os seus sentimentos inconscientes.

Para Sandler (apud GRUDTNER, 2009, p.18), a contratransferência é vista como "um conjunto de respostas emocionais específicas despertadas no médico pelas qualidades específicas de seu paciente".

O porquê da contratransferência? É o que, muitas vezes, nos perguntamos. Figueiredo (apud PALHARES, 2008, p. 103) registra que

esta contratransferência primordial corresponde justamente à disponibilidade humana para funcionar como suporte de transferências e de outras modalidades de demandas afetivas e comportamentais profundas e primitivas, vindo a ser um deixar-se afetar e interpelar pelo sofrimento alheio no que tem de desmesurado e mesmo incomensurável, não só de desconhecido como incompreensível.

Peres e Leite (2009, p. 6) afirmam que

dentro de uma relação terapêutica o profissional muitas vezes percebe-se invadido por sentimentos que se apresentam em reação ao funcionamento do paciente. Estes sentimentos podem acarretar em comportamentos facilitadores ou prejudiciais ao tratamento 
Silva e Lopes (2012, p. 20), por sua vez, quando registram sobre o manejo da contratransferência, afirmam que "além de reforçar o vínculo e a aliança terapêutica, a utilização da contratransferência mostrou-se como fonte de um importante suporte psicológico para o paciente, mantendo vivo o compromisso terapêutico".

O reconhecimento da transferência e contratransferência na relação médico-paciente-família pode capacitar melhor a equipe de saúde a utilizar seu arsenal defensório de forma a lhe proporcionar maior equilíbrio e segurança emocional neste momento difícil. (MENDES, 2009, p. 168).

Essas duas ferramentas atravessam a relação da tríade médico-criança-família e atuam no processo de aprendizado de como lidar com essa nova situação.

\footnotetext{
O processo educacional em saúde para a família da criança com PC está diretamente ligado ao relacionamento estabelecido entre profissionais e família...é imprescindível que se estabeleça o vinculo entre ambas as partes para que um espaço favorável seja criado, a fim de que a família coloque suas dúvidas, angustia e questionamentos e o profissional exerça a escuta terapêutica. (SANDOR, 2014, p.423)
}

\section{CONCLUSÃO}

Podemos perceber, dessa forma, que a paralisia cerebral pode implicar em algumas limitações para a criança acometida, exigindo dos cuidadores uma atenção mais acentuada. As suas implicações não interferem apenas no sistema locomotor, mas, em alguns casos, nas sensações, no comportamento, na cognição e no próprio relacionamento com o mundo que o cerca.

O impacto desse diagnóstico para os pais é algo que evoca uma tempestade de sentimentos e emoções, causando dificuldades com a organização interna desses sentimentos conflituosos. No cenário desse conflito estão diferentes atores, inclusive a figura do médico, que pode ser vista como o carrasco que trouxe a notícia tão indesejada ou a do redentor, que trará respostas às mais temíveis indagações. 0 médico acaba por assumir um protótipo, nem sempre o mais desejado. E o próprio médico se vê frente ao seu maior fantasma, suas limitações humanas.

A transferência está implícita como podemos ver nas relações humanas e, mais ainda, na teia que se estabelece no contato do médico com o paciente.

Ao relatar o diagnóstico aos pais da criança portadora de paralisia cerebral, pressupõe-se que o médico já tenha estabelecido uma boa relação médico-paciente-pais. É quase inevitável que esses pais depositem sobre o ícone médico uma figura das séries parietais, seja de pai, mãe ou qualquer outra capaz de reduzir sua ansiedade naquele momento. 0 ideal é que se estabeleça uma transferência positiva que propicia ganhos para a relação e para a criança em questão.

Podemos observar, então, que o processo de transferência implica numa atribuição de personagem de sua série infantil à figura do médico, com deslocamento de carga afetiva, que serve como alicerce e substrato para os próprios resultados do tratamento.

Não podemos nos esquecer também de que o conceito de transferência está atrelado ao de repetição. Logo, é necessário que o médico entenda que, algumas atitudes referendadas pelos pais da criança a ele não são de caráter pessoal, mas são direcionadas ao personagem que ele exerce naquela situação. 
No cenário da relação médico-paciente-pais, não é apenas o paciente e os pais que têm seus afetos em deslocamento e catexias, mas também o médico que está longe da neutralidade sonhada pelo positivismo. Não há, em uma relação humana, como afetar sem ser afetado, já que é uma estrada de mão dupla. As emoções e sentimentos do médico também estão em jogo diante do diagnóstico de paralisia cerebral ou mesmo de qualquer outro que traga comprometimentos para o paciente.

A contratransferência pode se tornar facilitadora ou prejudicial ao tratamento do paciente e o manejo que o médico faz dela poderá servir de ferramenta terapêutica tanto para a criança que está sob seus cuidados como para os pais que estão depositando nele sua confiança.

O manejo da transferência e contratransferência pode ser utilizado, dessa forma como instrumento terapêutico para o médico. Compreender o comportamento e a atuação do paciente e dos pais frente à essa situação difícil ajuda o médico a elaborar junto com os mesmos um melhor plano de ação, possibilitando ações preventivas ou mesmo reduzindo possíveis danos. 


\section{REFERÊNCIAS:}

ANDRADE, M. B. de; VIEIRA, S. de S.; DUPAS, G. Paralisia cerebral: estudo sobre o enfrentamento familiar. Revista Mineira de Enfermagem. Minas Gerais,v.15, n.1,p.86-96, jan-out de 2011.

BERNARDINO, L. M.F. A contribuição da psicanálise para a atuação no campo da educação especial. Estilos da clínica, São Paulo, v.12, n. 22, p. 48-67, 2007.

CHAGAS, P. S.C. et al.Classificação da função motora e do desempenho funcional de crianças com paralisia cerebral. Rev. Brasileira de Fisioterapia, v.12, n 5, p. 409-416, 2008.

DANTAS,M.S.de A.,COLLET, N. , MOURA, F. M. de ,TORQUATO, I.M.B. Impacto do diagnóstico de Paralisia Cerebral para a família. Texto Contexto-enfermagem. Florianópolis,v.19, n 2,p. 229-237, apr-jun. de 2010.

FREUD, S.A dinâmica da transferência.(1911/1913) In: Edição standard brasileira das obras psicológicas completas de Sigmund Freud.V. XII Rio de Janeiro: Imago, 1996.

FREUD, S. Conferências introdutórias sobre psicanálise(1916/1976). Conferência XXVII. In: Edição: Standard brasileira das obras psicológicas completas de Sigmund Freud. V.16,Rio de Janeiro: Imago, 1996.

GRUDTNER, R.R. Estudo da contratransferência e sua associação com características do paciente em psicoterapia de orientação analítica. Dissertação de Mestrado, Universidade Federal do Rio Grande do Sul, Porto Alegre, RS, 2009.

JACQUES, L. 0 seminário- livro 11: os quatro conceitos fundamentais da psicanálise.. $2^{\mathrm{a}}$ ed. Rio de Janeiro: J. Zahar, 1996.

LAPLANCHE,J., PONTALIS,J.B. Vocabulário de psicanálise. 4ª ed. São Paulo: Martins Fontes, 2004.

LEITE,L.,PERES, G.P. A contratransferência na abordagem psicanalítica e cognitivo-comportamental: duas perspectivas, uma só importância. Disponível em: <http://www.psicologia.pt/artigos/textos/ TL0134.pdf>, acesso em 16 out. 2012.

MARX, C., RODRIGUES,E.M., RODRIGUES, M.M., VILANOVA, L.C.P. Depressão, ansiedade, e sonolência diurna em cuidadores primários de crianças com paralisia cerebral. Rev. Paulista de Pediatria, São Paulo,vol. 29, n 4, p.483-488, dez 2011.

MENCARELLI, V. L. Compaixão na Contratransferência: cuidado emocional a jovens HIV +(S).Tese de Doutorado, Universidade de São Paulo, Instituto de Psicologia, São Paulo, S.P, 2010.

MENDES, J. A., LUSTOSA, M. A., ANDRADE, M.C.M. Paciente terminal, família e equipe de saúde. Rev. SBPH (on line), v. 12, n 1, p. 153-173, 2009.

MILBRATH, M.M. Cuidado da família à criança portadora de paralisia cerebral nos três primeiros anos de vida (dissertação). Rio Grande (RS): Fundação Universidade Federal de Rio Grande, Escola de Enfermagem; Rio Grande do Sul, 2008.

MILBRATH, V.M., SIQUEIRA, H.C.H. de, MOTTA, M. Da G.C. da, AMESTOY, S.C. Família da criança com Paralisia Cerebral: percepção sobre as orientações da equipe de saúde. Texto contexto- enfermagem (on line). Florianópolis,v. 21, n 4, p.921-928, out/dez 2012. 
MILBRATH,V.M., SOARES, D.C., AMESTOY, S.C., CECAGNO,D., SIQUEIRA,H.C.H. De. Mães vivenciando o diagnóstico da paralisia cerebral em seus filhos. Rev. Gaúcha de Enfermagem. Porto Alegre (RS), v.30, n 3, p. 437-444, set. de 2009.

PALHARES, M. do C. A. Transferência e Contratransferência a clínica viva. Rev.Brasileira de Psicanálise. V.42, n1, p. 100-111, 2008.

POLITA, N. B.; TACLA, M. T. G. M. Rede e apoio social às famílias de crianças com paralisia cerebral. Rev . Escola Anna Nery. v.18, n.1. Rio de Janeiro. Jan/mar de 2014. p. 75-81.

PORTO, C.C. Semiologia Médica. $7^{a}$ ed. Rio de Janeiro: Guanabara Koogan, 2014.

PORTO, C.C. Semiologia Médica. 5a ed. Rio de Janeiro: Guanabara Koogan,2005.

REBEL, M. F; RODRIGUES, R. F.;ARAÚJO, A. P. de Q. C.; CORRÊA, C. L. Prognóstico motor e perspectivas atuais na Paralisia Cerebral. Rev. brasileira crescimento e desenvolvimento Humano. v.20, n.2. São Paulo. Agosto de 2010. p. 342-350.

RIBEIRO, M. F. M.; SOUZA, A. L. L.; VANDENBERGHE, L.; PORTO, C. C. Estresse Parenteral em mães de crianças e adolescentes com paralisia cerebral. Rev. Latino americana de enfermagem. V.20, n.3. Maiojunho de 2014. p.440-447.

ROSENBAUM, P. et al. A report: the definition and classification of cerebral palsy. Dev. Med. ChildNeurol. Suppl., 109: 8-14, 2007.

SANDOR, E. R. S.; MARCON, S. S.; FERREIRA, N. M. L. A, DUPAS, G. Demanda de apoio social pela família da criança com paralisia cerebral. Rev. eletrônica de enfermagem.v.16, n2. , abril-junho de 2014. Disponível em: <http://dx.doi.org/10.5216/ree.ve.v16i2.21112.doi:10-5216/ree.v16i2.21112>. acesso: 15 ago. 2014.

SILVA, C. X. et al. Criança com paralisia cerebral: Qual o impacto na vida do cuidador. Rev. Rene, v.11, número especial, p. 204-214, 2010.

SILVA, V.C. da, LOPEZ, V. B. 0 manejo da Contratransferência no contexto clínico. p. 1-25. Disponível em: <:http://psicologia.faccat.br/moodle/plungifile.php/197/course/section/98/vanessa.pdf >. Acesso em 16 out. 2012.

SINGULANI, M. Angústia e Caráter. Dissertação de mestrado em Psicanálise da UERJ, Rio de Janeiro, 2005.

ZANON, M.A, BATISTA, N.A. Qualidade de vida e grau de ansiedade e depressão em cuidadores de crianças com paralisia cerebral. Rev. Paulista de Pediatria. São Paulo, v. 30, n 3, p. 392-396, set 2012.

ZIMERMAN, D. E. Manual de técnica psicanalítica. Porto Alegre: Artmed, 2004. 